\title{
The Polytene Chromosomes of Anther Tapetum of Some Phaseolus Species
}

\author{
Gianna Carvalheira and Marcelo Guerra \\ Department of Genetics, CCB, Federal University of Pernambuco-UFPE, \\ Recife, 50.732-970, PE, Brazil
}

Accepted April 6, 1994

Polytene chromosomes have been found in several angiosperm families. In many aspects they differ from the classic diptera polytene chromosomes, sharing with them mainly the large number of chromonemes per chromosome unit. Whereas the discovery of diptera polytenics brought a large contribution to many areas of Genetics, the plant polytene chromosomes have resulted in a still quite limited countribution. Nagl $(1974,1978,1981)$ has reviewed the theme thoroughly.

Plant polytene chromosomes have been found mainly in some very specialized cells of ovules, young seeds and embryo suspensor tissues. The most extensively studied plant polytene chromosomes are that from embryo suspensor cells of Phaseolus coccineus and secondarily from $P$. vulgaris. More recently, polytene chromosomes were found in the anther tapetal cells of Vigna unguiculata (Guerra and Carvalheira 1994). In spite of the fact that Vigna and Phaseolus are very closely related genera (Steele 1976), polytene chromosomes were not observed in $\boldsymbol{V}$. unguiculata suspensor (Carvalheira 1993). Anther tapetum of Phaseolus species have been previously analysed by many authors (Pritchard and Hutton 1972, Buss and Lersten 1975, Johns et al. 1992) without any mention of polytenization. However, they were not directly interested in the chromatin organization of tapetal cells and worked with histological sections, which is not an adequate method of observing the chromatin structure (Guerra and Carvalheira 1994).

In this article, we describe, for the first time, the occurrence of polytene chromosomes in the anther tapetal cells of some Phaseolus species and compare their structure with that of Phaseolus embryo suspensor and Vigna tapetal cells.

\section{Materials and methods}

Seeds of Phaseolus acutifolius cv. G40002, P. lunatus cv. G25143, P. vulgaris cv. Gordo and the interespecific amphidiploid $P$. vulgaris $\times P$. acutifolius $\mathrm{cv} .18016 / 2$ were supplied by the Agricultural and Livestock Research Enterprise of the State of Pernambuco (IPA/EMBRAPA) and grown in pots in our Department. Flower buds from $P$. microcarpus originally proceeding from México (Tonalá, Jalisco) and registered in the CIAT (International Centre of Tropical Agriculture) as S.13295 DGD-449, were supplied by Pedro Ruaro (U.N.A.M.). Flower buds and seeds from a garden specimen of $P$. coccineus growing at Kew (England) were supplied by Peter Brandham (Royal Botanic Gardens, Kew). The seeds were planted in the garden of our Department (Recife) and a second sample of flower buds was collected. $P$. peduncularis is a common weed growing in our universitary campus (voucher reference: PAP$40)$.

Young flower buds were sliced longitudinally, fixed in ethanol-acetic acid $3: 1$ for 5 to 24 $\mathrm{hr}$, and then stored in the same vial at $-20^{\circ} \mathrm{C}$. Anthers of different sizes were dilacerated into a drop of $45 \%$ acetic acid and observed in phase contrast microscopy to check the correct stage. 
When large interphase or prophase nuclei were observed, the anther wall was removed and the remaining material was gently squashed, frozen in liquid nitrogen to permit removal of coverslip, air-dried and stained with Giemsa (Guerra 1983).

\section{Results}

The mitotic interphase nuclei of all species and the tetraploid hybrid analysed showed an areticulate structure with an almost unstainable chromatin reticulum and a variable number of

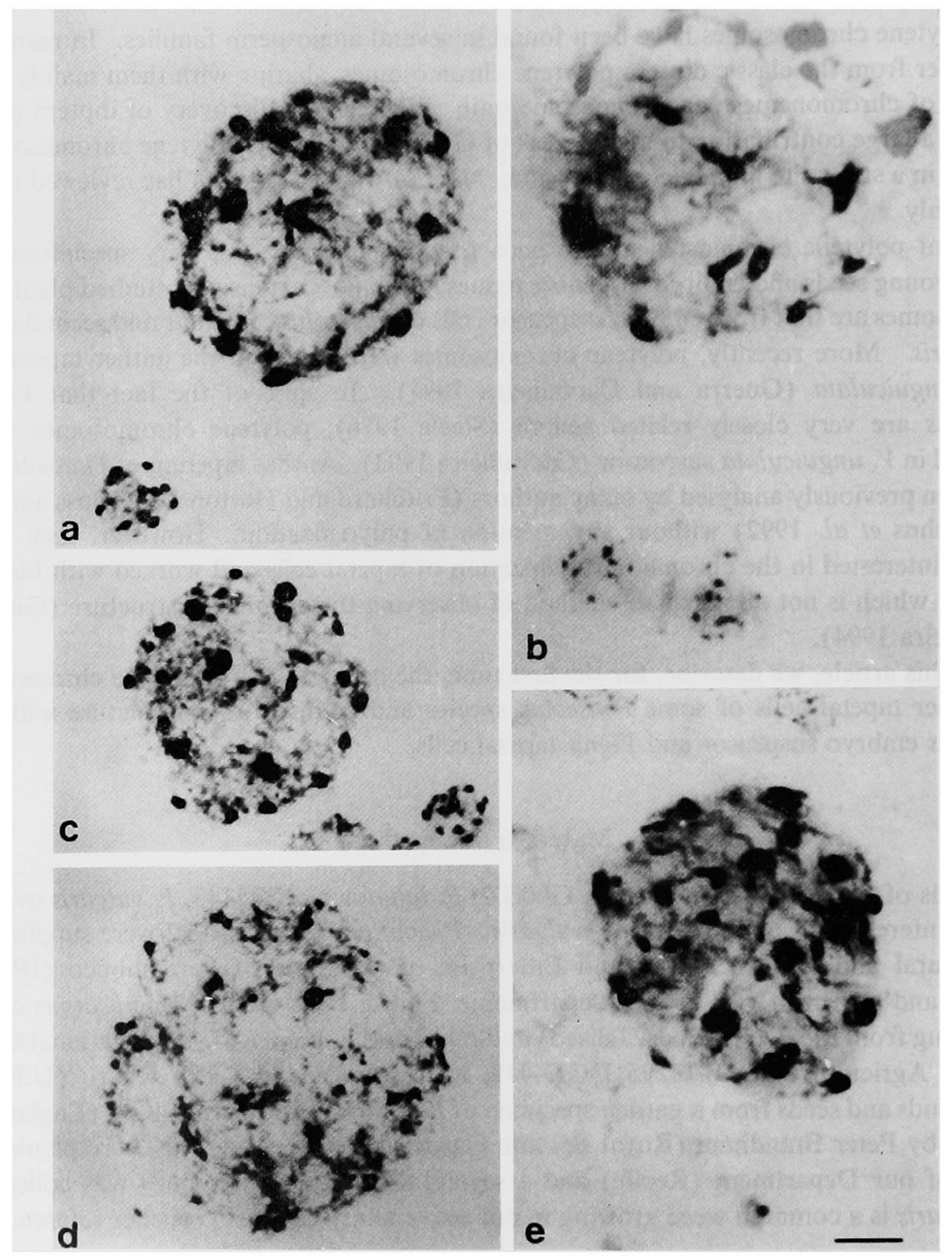

Fig. 1. Tapetal nuclei of Phaseolus species: a) P. acutifolius; b) P. lunatus; c) P. microcarpus; d) $P$. peduncularis; e) Amphidiploid $P$. acutifolius $\times P$. vulgaris. Note diploid nuclei in a, b and $\mathrm{c}$ (below). In e observe the large endochromocentres with associated thinner chromatid bundles. 
chromocentres. Phaseolus acutifolius and $P$. lunatus presented the more conspicuous contrast between the reticulum and the large and well delineated chromocentres (Fig. la, b).

The anther tapetal nuclei were identified by their large size from the beginning of the meiosis to the stage of microspore with well developed exine. Commonly, the nuclei became cytoplasm free, probably because their thin cell walls broke up easily during the squash preparation procedure. However, some cells showed a well delineated cytoplasm, as they had a harder cell wall (cell wall is usually not observed after $\mathrm{HCl}$ hydrolysis and Giemsa staining).

Tapetal cells of all species showed evidence of endoreduplication cycles. Besides the larger cells and nuclear size, their chromocentres progressively increased in size without changing in number. Until the end of the tetrad stage, when the tetrad callose wall was dissoluted, there was a large number of well developed tapetal nuclei. Thereafter, this number seemed to decrease whereas the endoreduplication level of individual nuclei appeared to become further enhanced. At this stage, polytene chromosomes characterized by chromatid bundles of variable extensions were more commonly observed.

The organization level of the polytene chromosomes was not the same in all species, showing a rather large variation. The extreme observed were $P$. acutifolius/P. lunatus, where chromatids bundles were rarely seen, in spite of relatively large size of their polytene cromocentres, or endochromocentres (Fig. 1a, b), and $P$. coccineus $/ P$. vulgaris, where bundled chromosomes were clearly observed (Fig. 2). P. microcarpus (Fig. 1c) and P. peduncularis (Fig. Id), despite their smaller and more numerous endochromocentres, were more similar to $P$. acutifolius and $P$. lunatus.

In general, there was a good relationship between the chromatin organization in mitotic interphase nuclei and in polytenic ones. Larger mitotic chromocentres, as in P. acutifolius, resulted in larger endochromocentres (Fig. 1a). Equally, species with denser chromatin reticulum in mitotic interphase presented more conspicuous chromatid bundles than that with strongly areticulate nuclei. The densest nuclei of all were those of the tetraploid hybrid (Fig. 1e).

$P$. coccineus called the attention due to its larger nuclei and better developed polytene chromosomes (Fig. 2a, b). Flower buds from the plants grown in the two different garden environments, one in Kew and another in Recife, showed no apparent differences in the chromatin organization of tapetal cells. In both gardens, the pollen development seemed to be normal, although in Recife the plants did not produce fruits. Noteworthy in this species was the occurrence of binucleate cells, whereas only mononucleate cells were found in the remaining species. Nuclei of binucleate cells seemed to present an equal polytenization level (Fig. 2a).

$P$. vulgaris showed polytene chromosomes smaller and thinner than $P$. coccineus, although chromatid bundling has been often observed (Fig. 2d). Beside such cells, nuclei with endochromocentres and without bundled chromatids, or incipient ones, were always present in both species (Fig. 2c).

The tetraploid hybrid $P$. acutifolius $\times P$. vulgaris $(2 \mathrm{n}=44)$ presented a high frequency of abnormal tetrads and different sized pollen grains. Nevertheless, a small number of pods attained maturity and some seeds were produced. Its anther tapetal nuclei were proportionally larger than those of diploid species. They clearly presented a summation of chromatin features from both parents (Figs. 1a, 2d), so that large endochromocentres were found together with conspicuous chromatid bundles (Fig. 1e). Very often the endochromocentres were disproportionally broader than the associated chromatin bundles (Fig. 1e). The number of large endochromocentres was variable but also higher in the hybrid than the summit of them in both parents. 


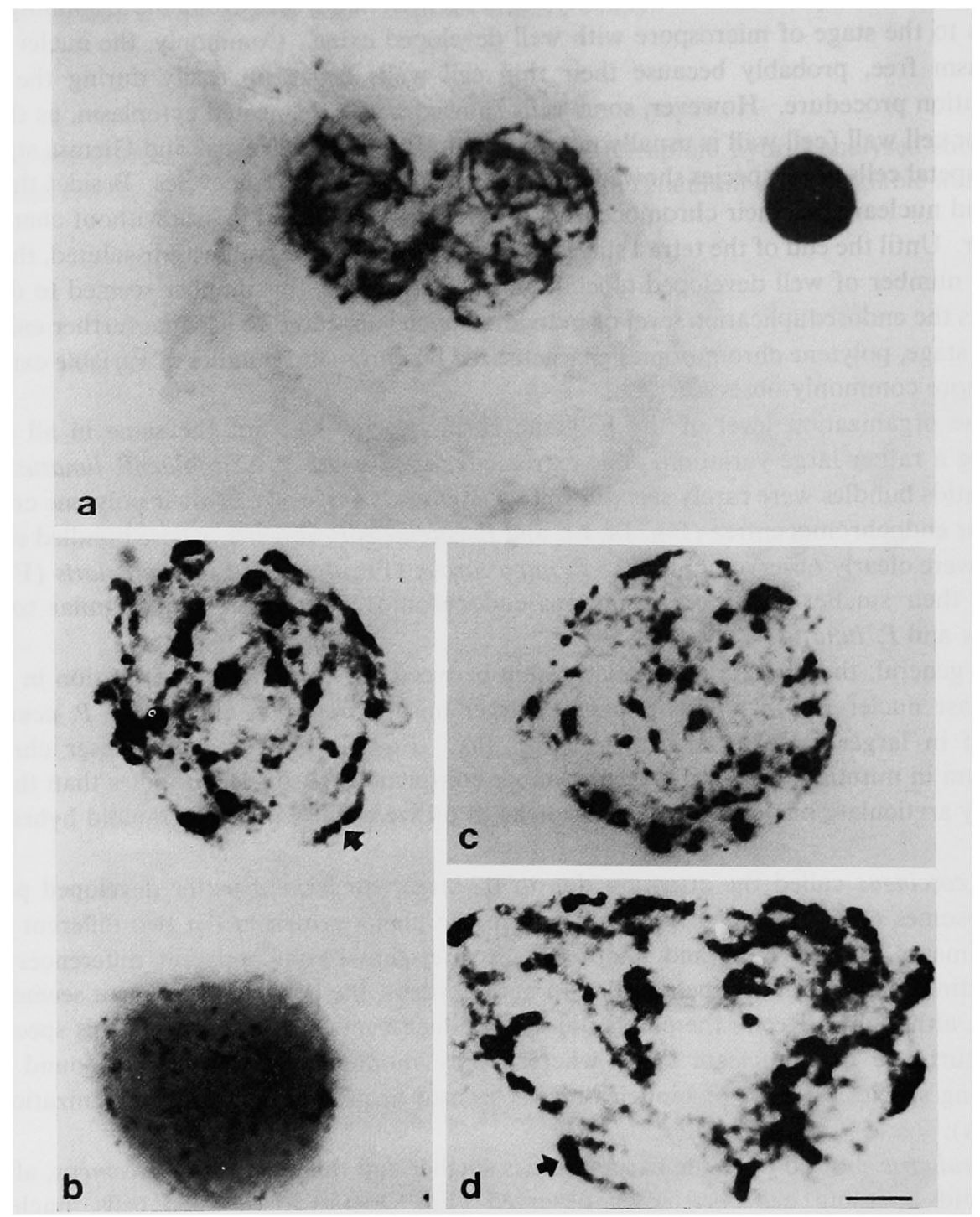

Fig. 2. Polytene nuclei of Phaseolus coccineus and $P$. vulgaris: a) Binucleate tapetal cell of $P$. coccineus displaying chromatid bundles in both nuclei. Dark ball at left is a strongly stained well developed microspore. b, c) Isolated polytene nuclei of $P$. coccineus at the anther microspore stage with bundle chromatids (b) and at the anther meiotic stage with only endochromocentres (c). Note microspore in b (below). d) Polytene nucleus of $P$. vulgaris with large proximal blocks. Arrows indicate centromeres. Bar represents $15 \mu \mathrm{m}$ for a and $8 \mu \mathrm{m}$ for $\mathrm{b}-\mathrm{d}$.

\section{Discussion}

As observed in the closely related genus Vigna (Guerra and Carvalheira 1994), the anther tapetal cells of Phaseolus showed endoreduplication cycles resulting in polytene chromosomes. In fact, endoreduplication is the most common mechanism to increase the DNA amount in the 
mononucleate tapetum (D'Amato 1984), although sister chromatid bundling forming distinguishable polytene units in tapetal cells has long been ignored.

The general morphology of the anther polytene chromosomes from $P$. coccineus and $P$. vulgaris during the maximum development stage seemed to be very similar between both species as well as among the known papilionoid genera with polytene chromosomes, as Lotus (Freed and Grant 1976), Psophocarpus (Sen 1980) and Vigna (Guerra and Carvalheira 1994). They presented a primary constriction and a variable extension of condensed proximal regions and diffuse terminal ones. The number and size of heterochromatic chromocentres seem to modify their polytene chromosome morphology in the same extension as they do in mitotic prophase chromosomes (Tschermak-Woess 1973). However, in our sample, the species with large endochromocentres did not develop chromatid bundling or did it poorly.

The variation in chromatin organization observed in tapetal cells was very similar to that reported in the embryo suspensor cells. Nagl (1974) investigated the suspensor cells from ten Phaseolus species and reported the occurrence of polytenization in only six of them. The remaining species presented large endochromocentres and diffuse chromatin. Among the six species investigated here, four ( $P$. acutifolius, $P$. coccineus, $P$. lunatus and $P$. vulgaris) were also analysed by Nagl. These species showed the same chromatin organization pattern in both tissues, although embryo suspensor cells seemed to present a proportionally higher maximum endoreduplication level. In both tissues, the best developed polytene chromosomes belong to $P$. coccineus. The chromatin of $\boldsymbol{P}$. acutifolius, on the other hand, was chracterized by Nagl as presenting "endochromocentres, unbundled euchromatic portions" and that of $P$. lunatus as presenting "no bundling trend". Exactly the same description applies to the chromatin of tapetal cells.

Tapetal nuclei are identifiable by their enhanced size since the outset of the meiosis, when they still maintain a diploid DNA amount. During the meiosis they undergo endocycles until the time of tetrad stage, when the tapetum degeneration takes place in most species (Carniel 1963, D'Amato 1984). Pritchard and Hutton (1972) reported the tapetum degeneration in Phaseolus atropurpureus as beginning at the end of the tetrad stage and advancing until the full exine development. However, we observed that just during this last stage the tapetal nuclei of Phaseolus species attained their highest developmental level, although the number of nuclei seemed to decrease. Also in Vigna such nuclei seemed to be more active exactly at this final stage, judging from its larger chromosome and nucleolus size (Guerra and Carvalheira 1994). This disagreement may reflect the difficulty to observe the chromatin organization through histological sections used by most authors (Guerra and Carvalheira 1994).

Plant polytene chromosomes have been interpreted as interphase structures, like diptera polytenics (Nagl 1981). However, our observations on tapetal cells of Vigna (Guerra and Carvalheira 1994) and Phaseolus suggest that such chromosomes may present cycles of diffuse and condensed states. In the diffuse state, only endochromocentres and sometimes the diffuse chromatin are visible. The number, size, shape and other features of the endochromocentres correspond to that of the mitotic chromocentres. In the condensed state, the bundled sister chromatids become identifiable as polytene chromosomes properly. They show a variable condensed region and one or two terminal decondensed regions, as in a mitotic prophase. A similar coiling cycle was observed in the embryo suspensor cells of Psophocarpus tetragonolobus (Sen 1980).

The change from diffuse to condensed state seems to depend mainly on the endoreduplication level, genetic background and environmental factors. Brady (1973) observed in Phaseolus coccineus suspensor that only cells with a DNA content higher than $64 \mathrm{C}$ presented polytene chromosomes. On the other hand, embryo suspensor cells with $256 \mathrm{C}$ showed polytene chromosomes in $P$. caffer and $P$. tuberosus, but not in $P$. lunatus, $P$. acutifolius or $P$. vulgaris var. 
Perlick (Nagl 1974), suggesting a genomic or genic dependence. The polytene chromosome morphology may also be strongly influenced by several physical and chemical factors (Nagl 1970, 1971, 1973). Furthermore, tightly bundled polytene chromosomes have been induced in cultured root and cotyledon cells of Pisum (Marks and Davies 1979, Therman and Murashige 1984), a species where polytene chromosomes were never reported in natura. All these observations point out that bundled polytene chromosomes of plants are more probably the consequence of advanced endoreduplication cycles which result in prophase or prophase-like chromosomes that may be still able to realize some DNA and RNA synthesis (Brady and Clutter 1974, Cionini et al. 1982).

\section{Summary}

The chromatin organization of tapetal cells of some Phaseolus species was analysed with Giemsa staining. They presented endoreduplication cycles which may result in large endochromocentres or more or less condensed chromatid bundles, visualized as polytene chromosomes, properly. $P$. coccineus and $P$. vulgaris showed the best developed polytenics, whereas $P$. acutifolius, $P$. lunatus, $P$. microcarpus and $P$. peduncularis, showed endochromocentres eventually associated with small chromatid bundles. The tetraploid hybrid $P$. acutifolius $\times P$. vulgaris showed tapetal nuclei with the characteristics of both parents. The ability to bundling the sister chromatids was intrinsic to each species and was similar to that previously reported in embryo suspensor cells. The polytene chromosome morphology and the change from dispersed state to a more condensed one suggest the occurrence of a coiling cycle which seemed to advance in the endoprophase more often and deeper in $P$. coccineus and $P$. vulgaris than in the remainder species.

\section{Acknowledgements}

We would like to thank Dr. Peter Brandham, Dr. Pedro Ruaro, the CIAT and the IPA/EMBRAPA for providing Phaseolus material and David Percy for corretions of the English manuscript.

\section{References}

Brady, T. 1973. Feulgen cytophotometric determination of the DNA content of the embryo proper and suspensor cells of Phaseolus coccineus. Cell Differ. 2: 65-67.

— and Clutter, M. E. 1974. Structure and replication of Phaseolus polytene chromosomes. Chromosoma 45: 63-79.

Buss Jr., P. A. and Lersten, N. R. 1975. Survey of tapetal nuclear number as a taxonomic character in Leguminosae. Bot. Gaz. 136: 388-395.

Carniel, K. 1963. Das Antherentapetum. Österr. Bot. Zeitschr. 110: 145-176.

Carvalheira, G. M. G. 1993. Análise comparativa entre cromossomos mitóticos e politênicos de Vigna unguiculata, de um híbrido tetraplóide Phaseolus acutifolius $\times P$. vulgaris e de seus parentais. Master Thesis, Federal University of Pernambuco, Recife, pp. 1-107.

Cionini, P. G., Cavallini, A., Corsi, R. and Fogli, M. 1982. Comparison of homologous polytene chromosomes on Phaseolus coccineus embryo suspensor cells: Morphological, autoradiographic and cytophotometric analysis. Chromosoma 86: 383-396.

D'Amato, F. 1984. Role of polyploidy in reprodutive organs and tissues. In "Embryology of Angiosperms". (B. M. Johri, ed. ), pp. 519-566. Springer-Verlag. Berlin.

Freed, H. J. and Grant, W. F. 1976. Polytene chromosomes in the suspensor cells of Lotus (Fabaceae). Caryologia 29: $387-390$.

Guerra, M. 1983. O uso do corante Giemsa na citogenética vegetal: Comparaçào entre a coloração simples e o bandeamento. Ciên. e Cult. 35: 190-193.

- and Carvalheira, G. M. G. 1994. Occurrence of polytene chromosomes in the anther tapetum of Vigna unguiculata 
(L.) Walp. J. Hered. 85: 43-46.

Johns, C., Lu, M., Lysnik, a. and Mackenzie, S. A. 1992. Mitochondrial DNA sequence is associated with abnormal pollen development in cytoplasmic male sterile bean plant. Plant Cell 4: 435-449.

Marks, G. E. and Davies, D. R. 1979. The cytology of cotyledon cells and the indution of giant polytene chromosomes in Pisum sativum. Protoplasma 101: 73-80.

Nagl, W. 1970. Temperature-dependent finctional structure in the polytene chromosomes of Phaseolus, with special reference to the nucleolus organizers. J. Cell Sci. 6: 87-107.

- 1971. Gibberellinsäure-stimulierte Genaktivität in Endosperm von Phaseolus. Planta 96: 145-151.

- 1973. Photoperiodic control of activity of suspensor polytene chromosomes in Phaseolus vulgaris. Z. Pflanzenphysiol. 70: 350-357.

- 1974. The Phaseolus suspensor and its polytene chromosomes. Z. Pflanzenphysiol. 73 : 1-44.

- 1978. "Endopolyploidy and Polyteny in Differentiation and Evolution". Amsterdam: North-Holland Publishing, p. 283.

- 1981. Polytene chromosomes of plants. Inter Rev. Cytol. 73: 21-53.

Pritchard, A. J. and Hutton, E. M. 1972. Anther and pollen development in male-sterile Phaseolus atropurpureus. J. Hered. 63: 280-282.

Sen, S. 1980. Evidence of coiling cycle in polytenic chromosome of suspensor cell. Nucleus 23: 88-89.

Steele, W. M. 1976. Cowpeas. In "Evolution of Crop Plants". (N.W. Simmonds, ed.), pp. 183-185. Longman Group. London.

Therman, E. and Murashige, T. 1984. Polytene chromosomes in cultivated pea roots (Pisum, Fabaceae). Plant Syst. Evol. 148: 25-33.

Tschermak-Woess, E. 1973. Somatische Polyploidie bei Pflanzen. In "Grundlagen der Cytologie". (G. C. Hirsh, H Ruska and P. Sitte, eds.), pp. 189-204. Fischer Verlag. Stuttgart. 